\section{Cultivation of Horsesickness Virus in Tissue Culture}

Nieschulz ${ }^{1}$ and Alexander ${ }^{2}$ independently showed that horsesickness virus multiplies in the brains of Swiss albino mice. Alexander ${ }^{3}$ reported later the successful cultivation of mouse-adapted horsesickness virus in the brains of guinea pigs, rats and other rodents. He also succeeded in cultivating a mouse-adapted strain of virus in embryonated hen's eggs, in which multiplication of the virus occurred in the brain of the embryo without producing any specific mortality ${ }^{4}$. McIntosh ${ }^{5}$ propagated viscerotropic horsesickness virus strains in 8-day-old embryonated hen's eggs at an optimum temperature of $32^{\circ} \mathrm{C}$. Embryo mortality occurred regularly during the initial passages.

This communication describes the successful propagation of horsesickness virus in tissue culture. The third mouse brain passage of a type 3 virus strain (designated as 13/63), with a mouse $L D_{50}$ titre of $10^{-6.0}$, was selected. After removal of the nutrient medium, roller tubes containing monolayers of chicken embryo fibroblasts were each seeded with $0.2 \mathrm{ml}$. of a 1 per cent suspension of the mouse brain antigen in Hanks's balanced salt solution. The inoculated tubes were rolled at $37^{\circ} \mathrm{C}$ for $30 \mathrm{~min}$ and the monolayers were then washed. Finally, each tube received $1.0 \mathrm{ml}$. of medium consisting of Hanks's balanced salt solution containing $\mathbf{0 . 5}$ per cent lactalbumen hydrolysate, 10 per cent bovine amniotic fluid and 2 per cent bovine serum. The tubes were kept in roller drums at $37^{\circ} \mathrm{C}$ and were examined daily under low magnification. No cytopathic effects were observed.

At daily intervals the supernatant fluid plus macerated cells of two tubes, selected at random, were titrated in day-old mice by intracerebral inoculation of decimal dilutions. The virus titres were calculated by the method of Reed and Muench ${ }^{6}$ and expressed as the negative logarithm of the dilution end-points. Table I represents the virus titres of the first three serial passages in chicken embryo fibroblasts.

Table 1

\begin{tabular}{ccccccccc} 
T.C. & \multicolumn{1}{c}{ Mouse $L D_{50}$ of tissue culture material on days after seeding } \\
passage & 1 & 2 & 3 & 4 & 5 & 6 & 7 & 8 \\
1st & $4 \cdot 0$ & $4 \cdot 0$ & $3 \cdot 5$ & $3 \cdot 7$ & $3 \cdot 0$ & $2 \cdot 9$ & $2 \cdot 5$ & $4 \cdot 0 *$ \\
2nd & - & - & $1 \cdot 0$ & $1 \cdot 0$ & $1 \cdot 5 *$ \\
3rd & 0 & $4 \cdot 0$ & $4 \cdot 0$ & $4 \cdot 0$ & $4 \cdot 0$ & $5 \cdot 0 *$ & \\
& \multicolumn{8}{c}{ Material used for passage. }
\end{tabular}

The specificity of the mortality in mice was controlled by a complement fixation test ${ }^{7}$ on the brains of mice sick after inoculation with material from the third and fifth tissue culture passages.

With the sixth passage the growth curve of the virus in tissue culture was determined. For this purpose a monolayer of chicken embryo fibroblasts in a 100-ml. medicine flat bottle was used. The culture was seeded as described before using $1.0 \mathrm{ml}$. of the fifth tissue culture passage of virus (titre $10^{-4.0}$ mouse $L D_{50}$ per $0.03 \mathrm{ml}$.) as seed material. After adsorption, the monolayer was washed, $10 \mathrm{ml}$. of medium was added and the bottle incubated at $37^{\circ} \mathrm{C}$. Aliquots of $1.0 \mathrm{ml}$. of supernatant fluid were removed daily from the bottle and titrated in day-old mice. One ml. of fresh medium was used to replace the sample removed.

In a parallel experiment a number of roller tubes were also seeded with virus as before and four tubes were collected daily. The supernatant fluids from each group of four tubes were collected, pooled and centrifuged to remove cellular material. The monolayers were washed three times with Hanks's balanced salt solution and then macerated in a volume of medium corresponding to the volume of supernatant fluid removed. Each sample of supernatant fluid and cells were titrated separately in mice. The results are summarized in Table 2.
Table 2

Culture

Mouse $L D_{60}$ of T.C. material on days after

\begin{tabular}{cccccc}
\multicolumn{7}{c}{ seeding } \\
1 & 2 & 3 & 4 & 5 & 6 \\
0 & $2 \cdot 5$ & 3.8 & $4 \cdot 2$ & 3.7 & $3 \cdot 9$ \\
0 & $2 \cdot 5$ & 3.8 & 4.8 & $4 \cdot 1$ & $4 \cdot 5$ \\
0 & 1.2 & $3 \cdot 7$ & 4.0 & 3.8 & $4 \cdot 2$
\end{tabular}

Bottle- $100 \mathrm{ml}$. flat

(b) Cells

$3 \cdot 7$

Although no specific cytopathic changes were noticed during six serial passages of the virus, it is quite evident from Tables 1 and 2 that monolayers of chicken embryo fibroblasts supported the growth of horsesickness virus under the conditions described. An appreciable amount of virus appeared to be cell bound.

By using the foregoing method, a type 4 horsesickness virus strain (designated as $32 / 62$ ) in its second mouse brain passage has also been adapted to multiply in chicken embryo tissue culture, and work is now in progress to adapt strains of the remaining seven types of horsesickness virus and to detormine optimal conditions of growth with special reference to cell type, $p \mathrm{H}$ and temperature of incubation.

I thank Dr. K. E. Weiss, head of the Virology Section of this Institute, for advice.

\section{B. J. Erasmus}

Section of Virology,

Veterinary Research Institute, Onderstepoort, South Africa.

${ }^{1}$ Nieschulz, O., Tydsch. Diergeneeskunde, 59, 1433 (1932).

"Alexander, R. A., J.S. Afr. Vet. Med. Assoc., 4, 1 (1933).

${ }^{3}$ Alexander, R. A., Onderstepoort J. Vet. Sci. Anim. Ind., 4, 291 (1935).

4 Alexander, R. A., Onderstepoort J. Vet. Sci. Anim. Ind., 11, 9 (1038).

MeIntosh, B. M. (unpublished observations).

- Reed, L. J., and Muench, H., Amer. J. Hyg., 27, 493 (1938).

'McIntosh, B. M., Onderstepoort J. Vet. Res., 27, 165 (1956).

\section{STATISTICS}

\section{Generalized Inverse of a Singular Matrix}

IN a recent communication ${ }^{2}$ a technique for obtaining a generalized inverse of a singular matrix $X=\left[\begin{array}{ll}A & B \\ C & D\end{array}\right]$, where the square sub-matrices $A$ and $D$ are non-singular, has been given. The $g$-inverse is derived in two stops, the first involving the calculation of an approximation, and the second its correction.

Dr. M. Zelen (private communication) has pointed out that in the expressions for the sub-matrices, corresponding to those of $X$, which correct the approximate $g$-inverse, two sub-matrices $\left(B D^{-1} C-A\right)$ and $\left(C A^{-1} B-D\right)$, which are both singular, are involved. That they are singular can be proved as follows.

Let $(\gamma, \delta)$ be a row vector such that the constituent vectors $\gamma$ and $\delta$ are non-zero, and their lengths aro equal to the number of rows in $A$ and $D$ respectively. Then since $X$ is singular :

$$
(\gamma, \delta)\left[\begin{array}{ll}
A & B \\
C & D
\end{array}\right]=0
$$

where 0 is a null vector of the same length as $(\gamma, \delta)$. Equation (1) yields the conditions $\gamma\left(B D^{-1} C-A\right)=0=$ $\delta\left(C A^{-1} B-D\right)$, and since $\gamma$ and $\delta$ are non-zero vectors, $\left(B D^{-1} C-A\right)$ and $\left(C A^{-1} B-D\right)$ must be singular.

However, despite this circumstance, the approximate $g$-inverse can still be corrected by using in the expressions for the correction matrix (already given by $\mathrm{me}$ ) the approximate $g$-inverses of these singular sub-matrices.

J. C. KOOP

Department of Experimental Statistics, University of North Carolina, Raleigh.

${ }^{1}$ Koop, J. C., Nature, 198, 1019 (1963). 